\title{
Ability of thawed tiger (Panthera tigris) spermatozoa to fertilize conspecific eggs and bind and penetrate domestic cat eggs in vitro
}

\author{
A. M. Donoghue ${ }^{1 *}$, L. A. Johnston ${ }^{1,2}$, U. S. Seal ${ }^{3}$, D. L. Armstrong ${ }^{2}$,
} L. G. Simmons ${ }^{2}$, T. Gross ${ }^{2}$, R. L. Tilson ${ }^{4}$ and D. E. Wildt ${ }^{1}$

${ }^{1}$ National Zoological Park, Smithsonian Institution, Washington DC, 20008, USA, ${ }^{2}$ Henry Doorly Zoo, Omaha, NE 68107, USA; ${ }^{3}$ Captive Breeding Specialist Group, Minneapolis, MN 55417, USA; and ${ }^{4}$ Minnesota Zoological Garden, Apple Valley, MN 55417, USA

\begin{abstract}
Summary. Electroejaculates from tigers were collected and half was used fresh to inseminate tiger eggs in vitro and domestic cat eggs stored in a hypertonic salt solution. The remainder was pelleted, frozen in a solution of $20 \%$ egg yolk, $11 \%$ lactose and $4 \%$ glycerol, thawed and cultured with tiger and domestic cat eggs. The motility index $(($ sperm $\%$ motility $)+($ status rating $\times 20)) / 2$ for thawed spermatozoa was about $86 \%$ of that in fresh aliquots. Of the 49 tiger oocytes inseminated in vitro with fresh spermatozoa, $34(69 \cdot 4 \%)$ cleaved, compared with 33 of 47 oocytes $(70 \cdot 2 \%)$ cultured with thawed spermatozoa $(P>0.05)$. Embryos generated by either sperm treatment could develop in vitro to the 16-cell or morula stage. Fresh and thawed tiger spermatozoa were equally capable $(P>0.05)$ of binding and penetrating the outer and inner zona pellucida of domestic cat eggs. These results demonstrate the ability of frozen-thawed tiger spermatozoa to (i) penetrate homologous and heterologous eggs and (ii) result in conspecific, advanced development of preimplantation embryos in vitro.
\end{abstract}

Keywords: tiger; spermatozoa; cryopreservation; in vitro fertilization; embryo

\section{Introduction}

Because native habitats for free-living tigers are rapidly diminishing, captive breeding has become essential for ensuring species survival and maintaining genetic diversity (Seal \& Foose, 1983). Captive propagation programmes, however, are burdened by limited space, geographic separation of individuals and the expense of sustaining a large, carnivorous species (McGuire \& Lacy, 1990). Because approximately 250 individuals of each of the five recognized tiger subspecies are required to maintain adequate genetic diversity (Foose, 1987), long-term conservation of tigers in captivity is expensive. For these reasons, there is practical justification for investigating assisted breeding techniques. For example, artificial insemination or in vitro fertilization (IVF) using frozen-thawed gametes and embryos could increase efficiency by reducing the number of sires required and extending the reproductive use of an individual well beyond its normal lifespan.

There is little information on the functionality of thawed, felid spermatozoa. Platz et al. (1978) reported the birth of kittens of domestic cats after vaginal artificial insemination of sedated females with thawed semen. Although the post-thaw sperm motility was $>50 \%$, pregnancy rate was $<11 \%$. Unfortunately, this type of strategy makes it impossible to identify the origin of reproductive inefficiency. Poor pregnancy rate in the study of Platz et al. (1978) could have been caused 
by factors ranging from freeze-induced sperm damage to delayed ovulation related to anaesthesia use (Howard et al., 1992). Compared with artificial insemination, IVF provides more fundamental information about the impact of external variables on gamete function and sperm-egg interaction (Wildt, 1990). Tigers are particularly attractive for such studies because an IVF system has already been developed that routinely results in $>63 \%$ of inseminated eggs forming cleaved embryos in vitro (Donoghue et al., 1990). Tiger embryos generated by IVF have also resulted in live young (Donoghue et al., 1990). The high efficiency of IVF in tigers, compared with that in other wild felids (Goodrowe et al., 1989; Miller et al., 1989; Donoghue et al., 1992), appears to be related to the ability of tigers to ejaculate semen containing high proportions of structurally normal spermatozoa of high motility (Donoghue et al., 1990; Wildt et al., 1992).

If gamete cryostorage is to be practical for assisting in the propagation of nondomestic species, it must be determined whether freeze-thawing compromises sperm function. This study assessed the ability of frozen-thawed tiger spermatozoa to bind, penetrate and fertilize eggs in vitro. Fresh and thawed sperm aliquots from tigers were cultured with conspecific, follicular eggs. Tiger spermatozoa were also incubated with domestic cat eggs stored in a hypertonic salt solution to confirm findings and to explore further the cross-species affinity of felid gametes (Howard \& Wildt, 1990). The latter eggs have been found useful for studying felid sperm capacitation (Andrews et al., 1992) and fertility potential in species producing many sperm pleiomorphisms (Howard et al., 1991a).

\section{Materials and Methods}

\section{Animals}

Four adult (5-13 year old), male tigers (two of Panthera tigris altaica and two of $P$. t. tigris) served as sperm donors and six adult (5-11 year old) females (two of $P$. t. altaica and four of $P$. t. tigris) as egg donors. All males were of proven fertility (on the basis of live cubs sired) or had produced consistently high quality electroejaculates in a previous study (Donoghue et al., 1990). Each tiger was housed separately with free access to an out-of-doors area $\left(5.5 \times 6.8 \mathrm{~m}^{2}\right)$ during daylight; at night, each tiger was confined indoors in a $2.6 \times 2.6 \mathrm{~m}^{2}$ enclosure. Each animal was fed a carnivore diet (Nebraska Brand Feline Diet, North Platte, NE, USA) daily and provided with water ad libitum.

\section{Collection, evaluation and cryopreservation of semen}

Ejaculates were collected using a standardized anaesthesia and electroejaculation technique reported previously (Wildt et al., 1983, 1987, 1988; Howard et al., 1986b; Donoghue et al., 1990). In brief, after inducing anaesthesia with ketamine hydrochloride (5.0 mg kg ${ }^{-1}$, i.m.; Vetalar: Parke-Davis, Detroit, MI, USA) and xylazine (0.5 $\mathrm{mg} \mathrm{kg}^{-1}$, i.m.; Rompun: Mombay Corp., KS, USA), a rectal probe with three longitudinal electrodes and an AC, $60 \mathrm{~Hz}$ sinewave ejaculator were used to deliver 80 electrical stimuli of 3-7 V over $20 \mathrm{~min}$. Total ejaculate volume was recorded, and each semen sample was examined immediately $(\times 25)$ for subjective estimates of $\%$ sperm motility and status (forward progression) or the type of forward movement of the sperm cell based on a scale of 0 (no movement) to 5 (steady, rapid forward progression). A sperm motility index, an overall evaluation of sperm motility characteristics, was calculated as follows: $((\%$ sperm motility $)+($ status rating $\times 20)) / 2$ (Howard et al., 1990). An aliquot of $10 \mu l$ of semen was used to calculate sperm concentration using a standard haemocytometer method (Howard et al., 1986b). Detailed sperm morphology was evaluated after fixing a $25 \mu \mathrm{l}$ aliquot in $1 \%$ glutaraldehyde and examining 300 individual spermatozoa per male at magnification of $\times 400$ (Howard et al., 1986b).

Each ejaculate was divided into two and half was used fresh for in vitro inseminations; the remainder was cryopreserved for use later in IVF attempts with thawed spermatozoa. Both aliquots were centrifuged ( $300 \mathrm{~g}$ for $8 \mathrm{~min}$ ), and the supernatant was removed. The fresh aliquot was resuspended in Ham's F10 medium containing $10 \%$ fetal calf serum (Irvine Scientific, Santa Ana, CA, USA) and maintained at room temperature $\left(23^{\circ} \mathrm{C}\right)$ for $1 \mathrm{~h}$ before use. The aliquot to be frozen was resuspended in $500 \mu \mathrm{l}$ PDV-62 (Howard et al., 1986a), a cryodiluent containing $20 \%$ egg yolk, $11 \%$ lactose and $4 \%$ glycerol and used previously for freezing spermatozoa of domestic cats (Platz et al., 1978). For sperm resuspension, the cryodiluent was added slowly and mixed gently with the sperm pellet at room temperature. The mixture was equilibrated for $30 \mathrm{~min}$ at $5^{\circ} \mathrm{C}$, then cooled rapidly on dry ice using a pelleting technique (Platz et al., 1978; Howard et al., 1986b) which generated approximately eight, $30 \mu \mathrm{l}$ drops per ejaculate. After $3 \mathrm{~min}$ on dry ice, the pellets were plunged into liquid nitrogen and stored at $-196^{\circ} \mathrm{C}$ for $30 \mathrm{~min}$.

Thawing involved transferring two pellets into a $5 \mathrm{ml}, 12 \times 75 \mathrm{~mm}^{2}$ glass tube containing $500 \mu \mathrm{l}$ Ham's F10 at $38^{\circ} \mathrm{C}$. The tube was shaken gently until the pellets were dissolved and, after $3 \mathrm{~min}$, an aliquot was examined 
microscopically for \% sperm motility, status and structural integrity. Fresh and thawed aliquots were diluted in Ham's F10 medium to an IVF insemination concentration $\left(0.5 \times 10^{6}\right.$ motile cells $\left.\mathrm{ml}^{-1}\right)$ and used immediately.

\section{Induction of ovarian activity, laparoscopy and recovery of eggs from tigers}

Female tigers were placed in a restraint cage and treated with a single 2500 iu dose of equine chorionic gonadotrophin (eCG, i.m., Equitech Inc., Atlanta, GA, USA) without regard to a specific stage of the reproductive cycle (Donoghue et al., 1990). The same method was used to inject each tiger with 2000 iu human chorionic gonadotrophin (hCG, i.m., Sigma Chemical Company, St Louis, MO, USA) $84 \mathrm{~h}$ later. Eggs were recovered $24-26 \mathrm{~h}$ after hCG using an anaesthesia and laparoscopic egg aspiration procedure described by Donoghue et al. (1990). In brief, anaesthesia was induced with xylazine $\left(0.5 \mathrm{mg} \mathrm{kg}^{-1}\right.$, i.m. $)$, diazepam $\left(0.1 \mathrm{mg} \mathrm{kg}^{-1}\right.$, i.m. Valium: Hoffman LaRoche, Nutley, NJ, USA) and ketamine $\mathrm{HCl} 0.5 \mathrm{mg} \mathrm{kg} \mathrm{g}^{-1}$, i.m. and each female was maintained on supplementary i.v. injections of ketamine $\mathrm{HCl}\left(1.5 \mathrm{mg} \mathrm{kg}^{-1}\right)$. A $180^{\circ}$ laparoscope, $10 \mathrm{~mm}$ in diameter (Richard Wolf Medical Instruments Corporation, Rosemont, IL, USA), was inserted through a $2 \mathrm{~cm}$ skin incision near the umbilicus and used to view the ovaries. A graduated Verres needle probe was used to measure follicular size and to secure the ovary for egg aspiration. A 22 gauge needle, $4 \mathrm{~cm}$ long attached to size 100 polyethylene tubing (i.d. $0.86 \mathrm{~mm}$; Clay Adams, Parsippany, NJ, USA) was rinsed with 2-3 ml of Ham's F10 medium (Irvine Scientific) containing $10 \%$ fetal calf serum (FCS, Irvine Scientific) and 40 units heparin $\mathrm{ml}^{-1}$ of medium. A siliconized collection tube (Terumo Medical Corporation, Elkton, MD, USA) was attached to the free end of the polyethylene tubing. All distinct follicles $\geq 2 \mathrm{~mm}$ in diameter were perforated with the needle while applying gentle negative pressure with a vacuum pump (Gast Manufacturing Corporation, Benton Harbor, MI, USA). Collection tubes from each animal were emptied into separate plastic culture dishes that were examined by stereomicroscopy. Each egg-cumulus cell complex was evaluated for maturation and classified as: (i) mature, if corona radiata and cumulus oophorus cells were loosened and expanded; (ii) immature, if the egg had a tightly compacted corona radiata; or (iii) degenerate, if the egg appeared abnormal, pale or lacked an apparent corona radiata (Goodrowe et al., 1988; Donoghue et al., 1990; Johnston et al., 1991a, b). Eggs were washed three times in Ham's F10 under light weight paraffin oil (Fisher Scientific Company, Fair Lawn, NJ, USA) and placed in fresh Ham's F10 without heparin.

\section{Storage of domestic cat eggs in a hypertonic salt solution}

Fresh ovaries of domestic cats were obtained from local veterinary clinics and maintained ex-situ in phosphatebuffered saline (Irvine Scientific) at $5^{\circ} \mathrm{C}$ for $1-4 \mathrm{~h}$ before processing. Ovaries were placed in Eagle's Minimum Essential Medium (Eagle's MEM; Sigma) supplemented with $5 \%$ FCS and punctured repeatedly with a 22 gauge needle to release cumulus-egg complexes. Eggs with homogeneously dark vitelli, tightly compacted corona radiata and cumulus cell masses were washed three times in fresh medium and cultured $\left(38^{\circ} \mathrm{C} ; 5 \% \mathrm{CO}_{2}, 5 \% \mathrm{O}_{2}, 90 \% \mathrm{~N}_{2}\right)$ in $0.5 \mathrm{ml}$ Eagle's MEM containing $0.23 \mathrm{mmol}$ pyruvate $1^{-1}, 1 \% \mathrm{FCS}, 3 \mathrm{mg}$ bovine serum albumin $\mathrm{ml}^{-1}$ and $1 \mu \mathrm{g}$ ovine follicle-stimulating hormone (FSH) $\mathrm{ml}^{-1}$ (NIADDK-oFSH-17 AFP-6446C), $1 \mu \mathrm{g}$ ovine luteinizing hormone (LH) $\mathrm{ml}^{-1}$ (NIADDK-oLH-25 AFP-5551B) and $25 \mu \mathrm{g}$ oestradiol ml ${ }^{-1}$ (Sigma Chemical Co.) (Johnston et al., 1991c). Cumulus cells were removed after maturation by transferring eggs to Eagle's MEM medium containing 0.2\% hyaluronidase for $15 \mathrm{~min}\left(38^{\circ} \mathrm{C}\right)$ and were then mechanically pipetted. Eggs were washed and transferred to the hypertonic salt storage solution (Boatman et al., 1988; Andrews et al., 1992) containing $0.5 \mathrm{~mol}\left(\mathrm{NH}_{4}\right)_{2} \mathrm{SO}_{4} \mathrm{I}^{-1}$, $0.75 \mathrm{~mol} \mathrm{MgCl}_{2} \mathrm{I}^{-1}, 0.2 \mathrm{mmol} \mathrm{ZnCl} \mathrm{I}^{-1}, 0.1 \mathrm{mg}$ polyvinylalcohol $\mathrm{ml}^{-1}$ and $40 \mathrm{mmol} \mathrm{Hepes} \mathrm{buffer} \mathrm{l}^{-1}(\mathrm{pH} 7 \cdot 4)$. The stored cat eggs with zonae pellucidae intact were maintained at $5^{\circ} \mathrm{C}$ until the day of insemination.

\section{Insemination of tiger eggs and assessment of fertilization and sperm longevity in vitro}

Mature eggs from an individual tiger were divided randomly into two groups and inseminated under oil with a $100 \mu \mathrm{l}$ aliquot of a diluted suspension containing $0.05 \times 10^{6}$ motile, fresh or frozen-thawed spermatozoa. Ten eggs or fewer were used per $100 \mu \mathrm{l}$ sperm drop, and the $35 \times 10 \mathrm{~mm}^{2}$ culture dishes were placed in a $5 \% \mathrm{CO}_{2}, 5 \% \mathrm{O}_{2}, 90 \%$ $\mathrm{N}_{2}$ humidified culture chamber at $38^{\circ} \mathrm{C}$ as described by Johnston et al. $(199 \mathrm{lb})$. As a control, one representative mature egg from each collection was cultured under these conditions without spermatozoa. All eggs were removed from the incubator $18-20 \mathrm{~h}$ after insemination, washed three times in a $0.2 \%$ hyaluronidase solution for $3 \mathrm{~min}$, returned to the incubator in $100 \mu \mathrm{l}$ drops of fresh Ham's F10 and examined for cleavage $30 \mathrm{~h}$ after insemination.

The longevity of sperm motility in vitro was determined by maintaining drops containing $100 \mu 1$ of the diluted sperm suspension containing either fresh or thawed spermatozoa (under the IVF conditions) without eggs for $4 \mathrm{~h}$ after insemination. A $10 \mu \mathrm{l}$ sample from each sperm drop was assessed every hour for $\%$ sperm motility and status, and these values were used to calculate sperm motility index profiles.

\section{Embryo culture}

The ability of tiger embryos generated from fresh versus thawed spermatozoa to develop further in vitro was determined by allowing embryos to grow in culture. After initial quality grading at $30 \mathrm{~h}$ after insemination, embryos were transferred into fresh Ham's F10 medium and examined for stage of development at 48 and $72 \mathrm{~h}$. 


\section{Insemination and evaluation of stored, domestic cat eggs}

The stored cat eggs were maintained at $5^{\circ} \mathrm{C}$ until the day of insemination, when they were rinsed and incubated twice ( $1.0 \mathrm{~h}$ per incubation) in standard IVF culture conditions consisting of Ham's F10 medium plus $5 \%$ FCS at $38^{\circ} \mathrm{C}$, in $5 \% \mathrm{CO}_{2}, 5 \% \mathrm{O}_{2}$ and $90 \% \mathrm{~N}_{2}$ (Johnston et al., 1991a, b). For each fresh and thawed aliquot, ten eggs were placed in a $100 \mu \mathrm{l}$ drop of Ham's F10 containing $0.05 \times 10^{6}$ motile spermatozoa under washed paraffin oil $\left(38^{\circ} \mathrm{C} ; 5 \% \mathrm{CO}_{2}, 5 \% \mathrm{O}_{2}, 90 \% \mathrm{~N}_{2}\right)$. After $6 \mathrm{~h}$ of incubation, eggs were fixed in a solution of $2 \%$ glutaraldehyde and $2 \%$ formaldehyde and stored at $5^{\circ} \mathrm{C}$. Using differential interference contrast (DIC) microscopy $(\times 400)$, a micromanipulator-holding pipette for manoeuvering the egg and previously described criteria (Howard et al., 1991a; Andrews et al., 1992), each egg was examined for number of (i) spermatozoa bound to the zona pellucida, (ii) sperm heads less than half-way through the zona pellucida, and (iii) sperm heads greater than half-way through the zona pellucida. The zona pellucida of the felid egg is distinctly divided into a diffuse outer layer and a dense inner layer and evaluation of the degree of sperm head penetration through each layer is evident using DIC microscopy (Andrews et al., 1992) (Fig. 2a). The percentage penetration for (ii) and (iii) was defined as the number of eggs with sperm penetrating the specific layer divided by the total number of eggs inseminated $\times 100$.

\section{Statistical analysis}

Mean values are presented as \pm SEM. $\chi^{2}$ analysis (Steel \& Torrie, 1960) was used to compare the effect of fresh versus thawed spermatozoa on the proportion of tiger eggs fertilized and the proportion of cat eggs penetrated.

\section{Results}

Sperm percentage motility at the time of electroejaculation was similar among males (range, $85 \cdot 0-90 \cdot 0 \%$ ) and, at the time of insemination ( $1 \mathrm{~h}$ later), had not decreased appreciably (Table 1 ). Freeze-thawing reduced sperm motility by $10-40 \%$ amongst males; sperm motility status averaged 4.5 before and 4.4 after thawing at the time of insemination. Compared with values of $87-95$ in ejaculates at the time of collection, sperm motility index ratings for individual males decreased by $7-25 \%$ after thawing. Fresh samples from males nos. 1, 2 and 4 maintained sperm motility index values $>60$ for $4 \mathrm{~h}$ after insemination (Fig. 1a), but sperm from male no. 3 maintained values $>60$ for only about $1 \mathrm{~h}$ after which motility decreased rapidly to zero. Although the mean sperm motility index at thawing differed by a value of only 11.3 in the fresh $(87.8 \pm 2.7)$ versus thawed $(76.5 \pm 1.9)$ groups at the time of insemination $(P<0.05)$, none of the thawed aliquots sustained a value $>60$ by $1 \mathrm{~h}$ later (Fig. Ib). The sperm motility index for the thawed aliquots of males no. 3 and 4 was $<20$ by $4 \mathrm{~h}$.

The proportion of structurally normal spermatozoa in the fresh ejaculate did not differ $(P>0.05)$ among males (mean, 86.3\%; Table 1 ). Of all abnormalities observed, the predominant pleiomorphisms were a bent midpiece $(5 \cdot 0 \%)$ and a proximal/distal droplet $(4 \cdot 0 \%)$. Freezethawing did not change $(P>0.05)$ the mean number of structurally normal cells (mean $83.8 \%)$ or the number of spermatozoa detected with the bent midpiece $(4.0 \%)$ and proximal/distal droplet $(4.3 \%)$ defects. After cryopreservation, $<3.0 \%$ of spermatozoa had abnormal acrosomes.

The mean numbers of ovarian follicles ( $\geq 2 \mathrm{~mm}$ in diameter) detected after injection with eCG $/$ hCG $(18.7 \pm 3.0)$ and eggs aspirated per female $(17.5 \pm 3.0)$ were similar to values measured in an earlier study in tigers (Donoghue et al., 1990). Four of the $106 \mathrm{eggs}$ collected (3.8\%) were classified as degenerate and none categorized as immature. The remaining eggs were mature and inseminated with either fresh $(n=49)$ or thawed $(n=47)$ spermatozoa or served as noninseminated controls $(n=6)$. None of the latter eggs cleaved, and there was no difference $(P>0.05)$ in the incidence of cleavage between treatments with fresh and thawed spermatozoa (Table 2). Spermatozoa from all males could produce embryos in vitro (percentage IVF rates for fresh and thawed sperm among males were no. $1: 78 \cdot 9,82 \cdot 3$; no. $2: 72 \cdot 7,72 \cdot 7$; no. $3: 16 \cdot 6,16 \cdot 6$; no. $4: 100$, 100, respectively). The poorest IVF rate involved male no. 3 , which coincidentally produced the most acute decline in sperm longevity in vitro (Fig. la, b).

Embryos produced by either sperm treatment developed in vitro at a comparable $(P>0.05)$ rate (Table 3). Most contained 2-4 blastomeres at $30 \mathrm{~h}$ and $4-8$ blastomeres at $48 \mathrm{~h}$. By $72 \mathrm{~h}$, more $(P<0.05)$ embryos had developed to the 16-cell stage in the thawed than in the fresh sperm group. 
Table 1. Semen characteristics of individual tiger electroejaculates

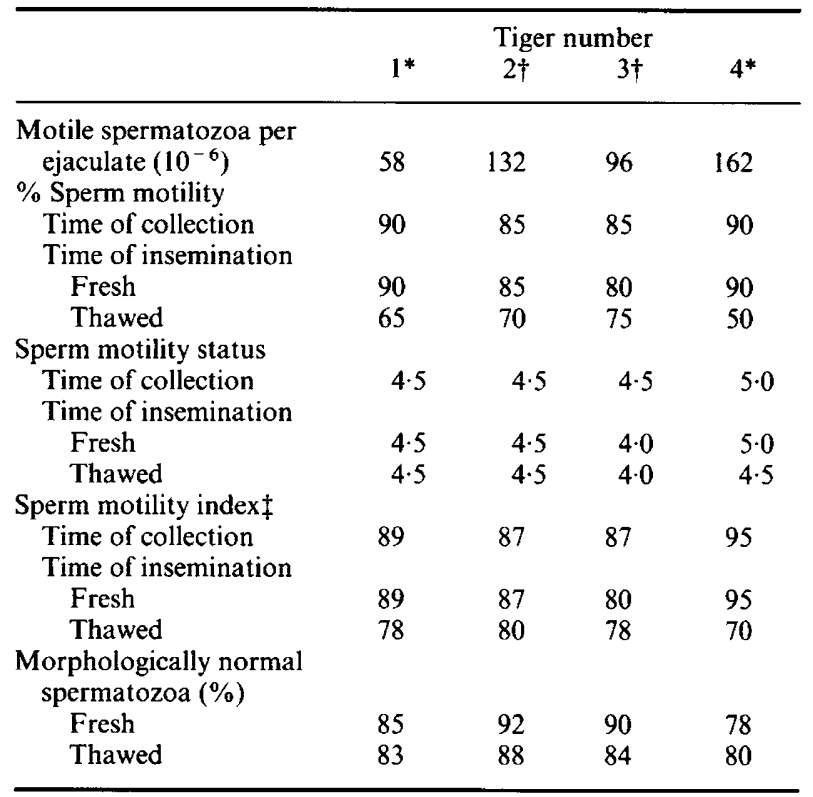

* Panthera tigris altaica male.

$\dagger$ P. t. tigris male.

$\$$ Sperm motility index $=($ sperm $\%$ motility $+($ sperm progressive motility $\times 20)) / 2$.
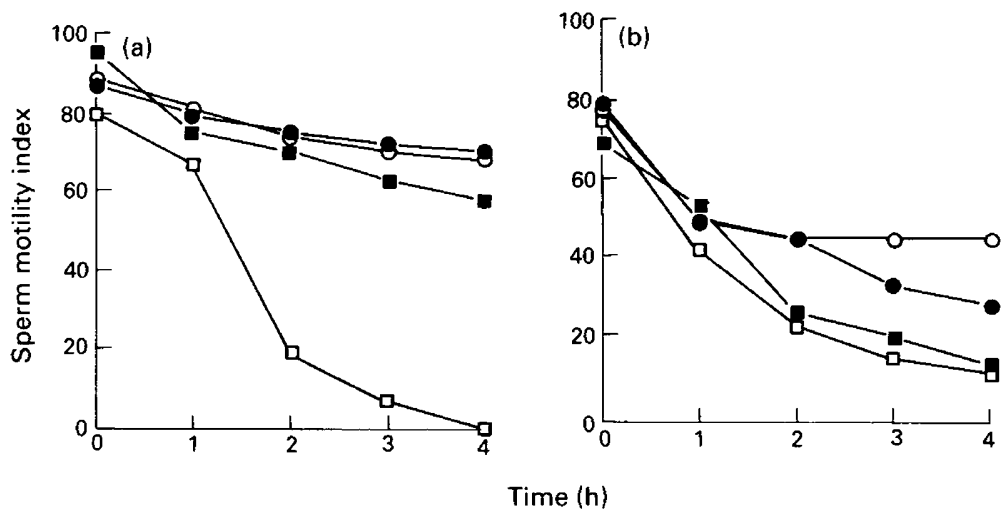

Fig. 1. Values of sperm motility index (see Table 1) for (a) fresh and (b) thawed spermatozoa from four tigers over time $(O)$ : no. $1 ;(\bigcirc)$ : no. $2 ;(\square)$ : no. $3 ;(\boldsymbol{\square})$ : no. 4 .

Fresh and thawed spermatozoa could bind and penetrate the outer and inner zona pellucida of domestic cat eggs (Table 2, Fig. 2a, b). The number of bound spermatozoa per egg was unaffected $(P>0.05)$ by individual male or the use of fresh versus thawed spermatozoa (data not shown); on average, $50 \cdot 2 \pm 10.8$ tiger spermatozoa were bound per egg in all males and sperm treatments. Regardless of whether fresh or thawed, tiger spermatozoa penetrated the two layers of the cat zona pellucida at similar rates (Table 2, Fig. 2a, b). However, overall, a much higher $(P<0.05)$ proportion of cat eggs had tiger spermatozoa in the outer $(86.6 \%)$ compared with the inner 
Table 2. Effect of fresh versus thawed tiger spermatozoa on fertilization of tiger eggs and penetration of zona pellucida of domestic cat eggs in vitro

\begin{tabular}{|c|c|c|}
\hline & Fresh & Thawed \\
\hline $\begin{array}{l}\text { Number of tiger eggs cleaving/ } \\
\text { number inseminated }(\%)\end{array}$ & $\begin{array}{c}34 / 49 \\
(69 \cdot 4 \%)\end{array}$ & $\begin{array}{c}33 / 47 \\
(70 \cdot 2 \%)\end{array}$ \\
\hline \multicolumn{3}{|l|}{$\begin{array}{l}\text { Sperm heads < halfway through } \\
\text { the zona pellucida }\end{array}$} \\
\hline $\begin{array}{l}\text { Number of cat eggs penetrated/ } \\
\text { number inseminated }(\%)\end{array}$ & $\begin{array}{c}35 / 41 \\
(85 \cdot 4 \%)\end{array}$ & $\begin{array}{c}36 / 41 \\
(87 \cdot 8 \%)\end{array}$ \\
\hline $\begin{array}{l}\text { Mean number of spermatozoa } \\
\text { per cat egg }\end{array}$ & $4.2 \pm 0.9$ & $5 \cdot 6 \pm 1 \cdot 0$ \\
\hline \multicolumn{3}{|l|}{$\begin{array}{l}\text { Sperm heads }>\text { halfway through } \\
\text { the zona pellucida }\end{array}$} \\
\hline $\begin{array}{l}\text { Number of cat eggs penetrated/ } \\
\text { number inseminated }(\%)\end{array}$ & $\begin{array}{c}13 / 41 \\
(31 \cdot 7 \%)\end{array}$ & $\begin{array}{c}20 / 41 \\
(48.9 \%)\end{array}$ \\
\hline $\begin{array}{l}\text { Mean number spermatozoa per } \\
\text { cat egg }\end{array}$ & $0 \cdot 3 \pm 0 \cdot 1$ & $0 \cdot 4 \pm 0 \cdot 2$ \\
\hline
\end{tabular}

Table 3. In vitro development of tiger embryos produced using fresh or frozen-thawed spermatozoa and in vitro fertilization

\begin{tabular}{|c|c|c|c|c|c|c|}
\hline \multirow{2}{*}{$\begin{array}{l}\text { Culture } \\
\text { interval }\end{array}$} & \multirow[b]{2}{*}{ Spermatozoa } & \multicolumn{5}{|c|}{ Stage of development } \\
\hline & & 2-cell & 4-cell & 8-cell & 16-cell & morula \\
\hline \multirow[t]{2}{*}{$30 \mathrm{~h}$} & Fresh & $20(58 \cdot 8)^{\mathrm{a}}$ & $13(38 \cdot 2)^{a}$ & $1(2.9)^{a}$ & - & - \\
\hline & Thawed & $18(54 \cdot 5)^{\mathrm{a}}$ & $14(42 \cdot 4)^{a}$ & $1(3 \cdot 0)^{a}$ & - & - \\
\hline \multirow[t]{2}{*}{$48 \mathrm{~h}$} & Fresh & $2(5.9)$ & $17(50 \cdot 0)^{a}$ & $14(41 \cdot 2)^{\mathrm{a}}$ & $1 \quad(2 \cdot 9)^{\mathrm{a}}$ & - \\
\hline & Thawed & - & $15(45 \cdot 4)^{a}$ & $16(48 \cdot 5)^{a}$ & $2(6 \cdot 1)^{\mathrm{a}}$ & - \\
\hline \multirow[t]{2}{*}{$72 \mathrm{~h}$} & Fresh & - & $5(14 \cdot 7)^{a}$ & $16(47 \cdot 1)^{a}$ & $9(26 \cdot 5)^{\mathrm{a}}$ & $4(11 \cdot 7)^{a}$ \\
\hline & Thawed & - & $6(18 \cdot 2)^{a}$ & $10(30 \cdot 3)^{b}$ & $14(42 \cdot 4)^{b}$ & $3(9 \cdot 1)^{a}$ \\
\hline
\end{tabular}

Values within columns with different superscripts $(P<0.05)$ are significantly different.

Numbers within columns represent individual eggs at particular stage by treatment group.

Percentages of totals in each treatment group in parentheses.

$(40.3 \%)$ half of the zona pellucida. Neither the proportion of zona pellucida penetrated (range $55.6 \%$ for male no. 1 to $100 \%$ for male no. 4) nor the mean of spermatozoa in the outer (range $2.8 \pm 1.7$ for male no. 3 to $5.9 \pm 1.6$ for male no. 2 ) or inner (range $0.2 \pm 0.1$ for male no. 3 to $0.4 \pm 0 \cdot 1$ for male no. 2 ) half of the zona pellucida were influenced by individual male.

\section{Discussion}

Electroejaculate and ovarian egg characteristics and subsequent IVF rates using fresh spermatozoa were consistent with earlier results (Wildt et al., 1987, 1988; Byers et al., 1989; Donoghue et al., 1990) indicating that the animals and gametes used here were typical for the tiger species. The results demonstrated that a conventional egg yolk-lactose-glycerol cryodiluent combined with a semen pelleting technique could be used to recover sperm motility after thawing and permitted comparatively high rates of fertilization and embryo development in vitro. This occurred despite a reduction in sperm motility of $5-40 \%$ caused by freeze-thawing. The finding that IVF and subsequent embryo culture rates did not differ between the fresh and thawed sperm treatments suggested that tiger spermatozoa were relatively unaffected by this cryopreservation approach. 
(a)

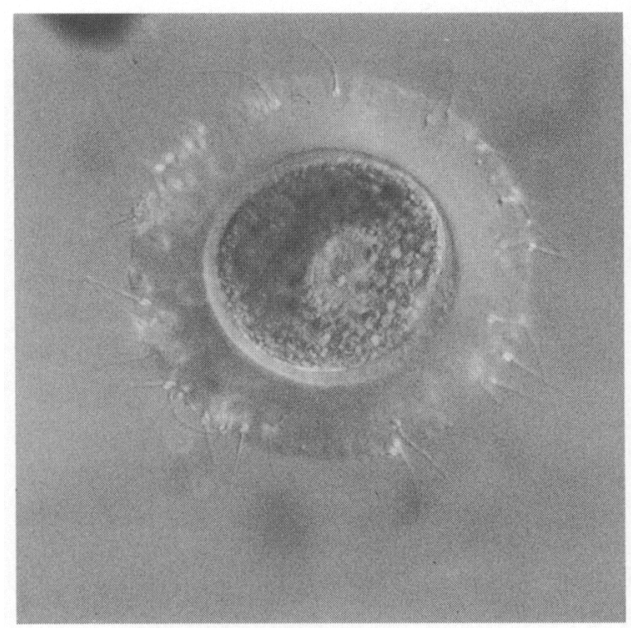

(b)

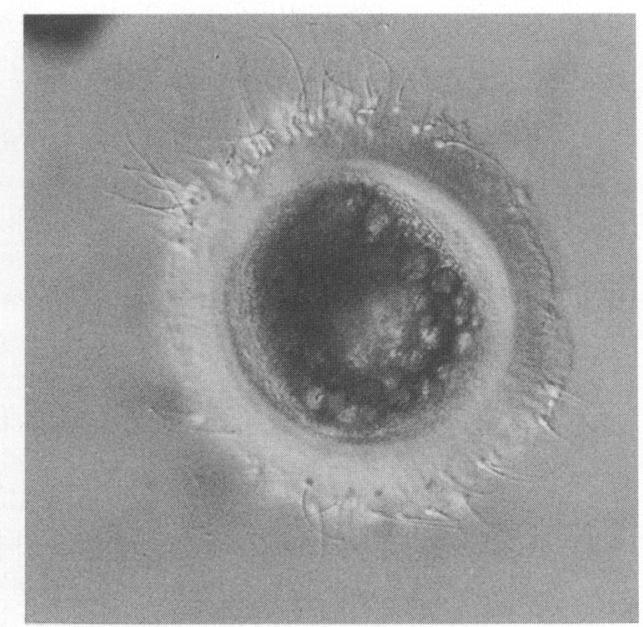

Fig. 2. Penetration of zona pellucida of domestic cat eggs with (a) fresh and (b) thawed tiger spermatozoa.

We have speculated (Donoghue et al., 1990) that one reason that tiger spermatozoa interact so readily with eggs in vitro is related to their robustness and the lack of structural abnormalities commonly observed in other felid species (Wildt et al., 1983, 1988; Howard et al., 1984; Miller et al., 1989; Donoghue et al., 1992). In nonfelid taxa, cryopreservation can cause extensive gross and ultrastructural sperm damage that can markedly compromise fertility (Pursel et al., 1972; Berndston et al., 1981). Especially important is acrosomal damage, the incidence of which has been related to the freezing technique, cryodiluent used and the thawing procedure (Pursel et al., 1972; Berndston et al., 1981; Howard et al., 1991b). The acrosome of all felid spermatozoa is too narrow to identify easily, making it a difficult structure to use as an index of sperm viability after freezing. In the present study, there was no evidence of increased gross sperm damage caused by cryopreservation as proven by the production of conspecific embryos in vitro. Nevertheless, it is possible that frozen-thawed tiger spermatozoa experienced some ultrastructural damage. As germ plasm storage strategies are developed, it is therefore important to assess sperm function using in vitro bioassays. Because conspecific eggs of endangered species may not always be available as test material, our coincidental finding that cat eggs were penetrated by tiger spermatozoa in vitro suggested that these heterologous gametes may be useful as test material.

A previous study (Byers et al., 1989) demonstrated that the motility of tiger spermatozoa frozen in straw containers in TEST extender decreases to $<6 \%$ within $2 \mathrm{~h}$ of thawing. We, therefore, chose the PDV-pelleting technique, proven effective in dogs (Platz \& Seager, 1977), cats (Platz et al., 1978) and ferrets (Howard et al., 1991b). Although sperm motility declined more rapidly in the thawed than in the fresh sample (Fig. 1), spermatozoa were still motile $4 \mathrm{~h}$ after insemination and lived at least twice as long in vitro than in the earlier study of Byers et al. (1989). Cryopreservation studies in other species, including the African elephant (Howard et al., 1986a) and ferret (Howard et al., 199lb), have demonstrated the superiority of the pelleting over the straw method. The cooling rate during freezing is one of the most important factors controlling cell viability (Mazur, 1985). In the earlier tiger study of Byers et al. (1989), samples were frozen at a rate of $-3^{\circ} \mathrm{C} \mathrm{min}^{-1}$ to $-40^{\circ} \mathrm{C}$, then at $-20^{\circ} \mathrm{C} \mathrm{min}^{-1}$ to $-100^{\circ} \mathrm{C}$ followed by plunging into liquid $\mathrm{N}_{2}$ at $-196^{\circ} \mathrm{C}$. In our study, samples were equilibrated at $5^{\circ} \mathrm{C}$ for $30 \mathrm{~min}$, rapidly cooled on dry ice for $3 \mathrm{~min}$ and then plunged. Compared with the straw freezing method, the pellet method may have provided faster freezing (Nagase \& Niwa, 1963; Howard et al., 1991b), resulting in a shorter duration of the freezing point plateau and reduced sperm damage. 
The proportion of tiger eggs fertilized with fresh or thawed spermatozoa from males that produced spermatozoa which lived for at least $4 \mathrm{~h}$ in culture was high (average, $72.4 \%$ ). However, sperm viability for male no. 3 in both the fresh and thawed groups and for male no. 4 in the thawed group, had decreased sharply $2 \mathrm{~h}$ after insemination. The poor survival rate of spermatozoa in vitro probably resulted in the low fertilization rate (average, 28.6\%). It was impossible to assess the impact of an individual male on results because only four males were evaluated and all produced high quality ejaculates. None the less, the ability of fresh versus thawed tiger spermatozoa to penetrate zona-free hamster eggs has been related to overall sperm survival (Byers et al., 1989). When hamster eggs were inseminated with spermatozoa with a post-thaw motility rating of $40 \%$, $7 \cdot 6 \%$ of hamster eggs were penetrated. However, when spermatozoa were preincubated for $2 \mathrm{~h}$, their motility decreased to $<10 \%$, and the penetration rate was zero (Byers et al., 1989). In a recent study, we found a high correlation between the sperm motility index of freshly ejaculated cheetah spermatozoa at $3 \mathrm{~h}$ after insemination and the ability of cheetah eggs to be penetrated and fertilized (Donoghue et al., 1992). When eggs from individual cheetahs were separated into two groups and inseminated with spermatozoa from a male with a high $(>40)$ versus a low $(\leqslant 40)$ sperm motility index, the mean fertilization rate was $64 \%$ versus $0 \%$, respectively. In the present study, the high proportion of tiger eggs that were fertilized may have been the result of prolonged sperm motility (motile at least $1 \mathrm{~h}$ after thawing), optimal timing of insemination or both. It is premature to speculate about the exact interrelationship between spermatozoa motility and sperm-egg interaction; however, these in vitro bioassays will provide a valuable approach for more thorough studies.

As gamete cryopreservation is adapted to nondomestic felids, biocompetency tests of postthawed material will be mandatory. Although IVF using conspecific eggs could be a valuable predictor of ability to fertilize, this strategy is difficult to implement owing to the lack of availability of eggs from the rare species of interest. Recent studies have demonstrated cross-species egg penetration and fertilization between domestic cat and nondomestic felid gametes (Howard \& Wildt, 1990; Howard et al., 1991a; Johnston et al., 1991c; Andrews et al., 1992). Domestic cat spermatozoa cultured with eggs from six nondomestic felid species are capable of fertilization and, in some instances, cleavage to early-stage embryos in vitro (Johnston et al., 1991c). Spermatozoa from leopard cats (Howard \& Wildt, 1990) and cheetahs (Howard et al., 1991 a) are also capable of binding and penetrating the zona pellucida of intact eggs from domestic cats in vitro. We observed that tiger spermatozoa could also bind and penetrate the zona pellucida of domestic cat eggs, thereby providing further evidence that in vitro gametes from different felid species readily interact. These findings suggest that the Felidae could serve as an excellent model taxon for further studies concerning zona pellucida receptor mechanisms associated with sperm penetration as well as cross-species limitations of sperm-egg interaction.

Embryos resulting from IVF with fresh or thawed tiger spermatozoa were capable of advancing in culture to the 16-cell or morula stage of development in vitro at a rate similar to our earlier observations in tigers (Donoghue et al., 1990) and domestic cats (Johnston et al., 1991a, b). We observed embryo development at $24 \mathrm{~h}$ intervals; therefore, time points may have preceded or followed cleavage times of embryos by a few hours. None the less, it was interesting that embryos from the group fertilized with thawed spermatozoa developed slightly in advance of the group fertilized with fresh spermatozoa. This was particularly noticeable after $72 \mathrm{~h}$ in culture. Byers et al. (1989) determined that freshly ejaculated tiger spermatozoa require a $2 \mathrm{~h}$ preincubation period before penetrating zona pellucida-free hamster eggs, whereas thawed spermatozoa can penetrate eggs immediately after insemination. The freeze-thaw process has been associated with partial or complete capacitation of spermatozoa and has been used to bypass insufficient capacitation of bovine spermatozoa in IVF studies (Parrish et al., 1986; Fukui et al., 1988).

In summary, we used two types of fertilization assays to confirm the ability of frozen-thawed tiger spermatozoa to fertilize in vitro. The biological competency of these frozen cells remains to be determined by the production of live young. However, the high incidence of fertilization and 
preimplantation embryo development measured here suggests that this technique for semen storage may be useful now in helping to sustain tiger genetic diversity.

We thank A. P. Byers, P. Wolff, K. Petrini, B. Joseph, M. A. Seal and L. Patton for their generous assistance. We are grateful to K. Roberts, Director of the Minnesota Zoo, N. J. Reindl, D. Morris and the veterinary and keeper staffs at the Minnesota Zoological Gardens and the Henry Doorly Zoo for their cooperation. This work was supported, in part, by grants from the Nixon Griffis Fund (to A. M. Donoghue) and from the National Institutes of Health (HD 23853), NOAHS Center, the Friends of the National Zoo and the Ralston Purina Big Cat Survival Fund administered by the American Association of Zoological Parks and Aquariums (to D. E. Wildt).

\section{References}

Andrews, J.C., Howard, J.G., Bavister, B.D. \& Wildt, D.E. (1992) Sperm capacitation in the domestic cat (Felis catus) and leopard cat (Felis bengalensis) studied with a salt-stored zona pellucida penetration assay. Molecular Reproduction and Development 31, $200-207$.

Berndston, W.E., Olar, T.T. \& Pickett, B.W. (1981) Correlation between post-thaw motility and acrosomal integrity of bovine sperm. Journal of Dairy Science 64, 346-349.

Boatman, D.E., Andrews, J.C. \& Bavister, B.D. (1988) A quantitative assay for capacitation: evaluation of multiple sperm penetration through the zona pellucida of salt-stored hamster eggs. Gamete Research 19, 19-29.

Byers, A.P., Hunter, A.G., Seal, U.S., Binczik, G.A., Graham, E.F., Reindl, N.J. \& Tilson, R.L. (1989) In vitro induction of capacitation of fresh and frozen spermatozoa of the Siberian tiger (Panthera tigris). Journal of Reproduction and Fertility 86, 599-607.

Donoghue, A.M., Johnston, L.A., Seal, U.S., Armstrong, D.L., Tilson, R.L., Wolf, P., Petrini, K., Simmons, L.G., Gross, T. \& Wildt, D.E. (1990) In vitro fertilization and embryo development in vitro and in vivo in the tiger (Panthera tigris). Biology of Reproduction 43, 733-744.

Donoghue, A.M., Howard, J.G., Byers, A.P., Goodrowe, K.L., Bush, M., Blumer, E., Lukas, J., Stover, J., Snodgrass, K. \& Wildt, D.E. (1992) Correlation of sperm viability with gamete interaction and fertilization in vitro in the cheetah (Acinonyx jubatus). Biology of Reproduction 46, 1047-1056.

Foose, T. (1987) Species survival plans and overall management strategies. In Tigers of the World: The Biology, Biopolitics, Management and Conservation of an Endangered Species, pp. 304-316. Eds R. L. Tilson \& U. S. Seal. Noyes Publications, Park Ridge.

Fukui, Y., Glew, A.M., Gandolfi, F. \& Moor, R.M. (1988) Ram-specific effects on in vitro fertilization and cleavage of sheep oocytes matured in vitro. Journal of Reproduction and Fertility 82, 337-340.

Goodrowe, K.L., Wall, R.J., O'Brien, S.J., Schmidt, P.M. \& Wildt, D.E. (1988) Developmental competence of domestic cat follicular oocytes after fertilization in vitro. Biology of Reproduction 39, 355-372.

Goodrowe, K.L., Miller, A.M. \& Wildt, D.E. (1989) In vitro fertilization of gonadotropin-stimulated leopard cat (Felis bengalensis) follicular oocytes. Journal of Experimental Zoology 252, 89-95.

Howard, J.G. \& Wildt, D.E. (1990) Ejaculate-hormonal characteristics in the leopard cat (Felis bengalensis) and sperm function as measured by in vitro penetration of zona-free hamster ova and zona-intact domestic cat oocytes. Molecular Reproduction and Development 26, 163-174.

Howard, J.G., Bush, M., Hall, L.L. \& Wildt, D.E. (1984) Morphological abnormalities in spermatozoa of 28 species of nondomestic felids. Proceedings of the Tenth International Congress on Animal Reproduction \& Artificial Insemination, Champaign, Illinois. Vol. 2, pp. 57-59.

Howard, J.G., Bush, M., de Vos, V., Schiewe, M.C., Pursel, V.G. \& Wildt, D.E. (1986a) Influence of cryoprotective diluent on post-thaw viability and acrosomal integrity of spermatozoa from the African elephant (Loxodonta africana). Journal of Reproduction and Fertility 78, 295-306.

Howard, J.G., Bush, M. \& Wildt, D.E. (1986b) Semen collection, analysis and cryopreservation in nondomestic mammals. In Current Therapy in Theriogenology, pp. 1047-1053. Ed. D. A. Morrow. W. B. Saunders Co., Philadelphia.

Howard, J.G., Brown, J.L., Bush, M. \& Wildt, D.E. (1990) Teratospermic and normospermic domestic cats: ejaculate traits, pituitary-gonadal hormones and improvement of spermatozoal motility and morphology after swim-up processing. Journal of Andrology 11, 204-215.

Howard, J.G., Barone, M.A., Bush, M. \& Wildt, D.E. (1991a) A heterologous salt-stored zonae pellucidae assay for assessing sperm capacitation and the impact of teratospermia in the cheetah (Acinonyx jubatus). Journal of Andrology Supplement 16, 101.

Howard, J.G., Bush, M., Morton, C., Morton, F., Wentzel, K. \& Wildt, D.E. (1991b) Comparative semen cryopreservation in ferrets (Mustela putorius furo) and pregnancies after laparoscopic intrauterine insemination with frozen-thawed spermatozoa. Journal of Reproduction and Fertility 92, 109-118.

Howard, J.G., Barone, M.A., Donoghue, A.M. \& Wildt, D.E. (1992) The effect of pre-ovulatory anaesthesia on ovulation in laparoscopically inseminated domestic cats. Journal of Reproduction and Fertility 96, 175-186.

Johnston, L.A., O'Brien, S.J. \& Wildt, D.E. (1989) In vitro maturation and fertilization of domestic cat follicular oocytes. Gamete Research 23, 343-356. 
Johnston, L.A., Donoghue, A.M., O'Brien, S.J. \& Wildt, D.E. (1991a) Culture medium and protein supplementation influence in vitro fertilization and embryo development in the domestic cat. Journal of Experimental Zoology 257, 350-359.

Johnston, L.A., Donoghue, A.M., O’Brien, S.J. \& Wildt, D.E. (1991b) Influence of temperature and gas atmosphere on in vitro fertilization and embryo development in the domestic cat. Journal of Reproduction and Fertility 92, 377-382.

Johnston, L.A., Donoghue, A.M., O'Brien, S.J. \& Wildt, D.E. (1991c) "Rescue" and maturation in vitro of follicular oocytes of nondomestic felid species. Biology of Reproduction 45, 898-906.

McGuire, L.A. \& Lacy, R. (1990) Allocating scarce resources for conservation of endangered subspecies: Partitioning zoo space for tigers. Conservation Biology 4, 157-166.

Mazur, P. (1985) Basic concepts in freezing cells. Praceedings of the First International Conference on Deep Freezing of Boar Semen, pp. 91-111. Eds L. A. Johnson \& K. Larsson, Swedish University of Agricultural Sciences, Uppsala.

Miller, A.M., Roelke, M.E., Goodrowe, K.L., Howard, J.G. \& Wildt, D.E. (1989) Oocyte recovery and fertilization in vitro in the puma (Felis concolor). Journal of Reproduction and Fertility 88, 249-258.

Nagase, H. \& Niwa, T. (1963) Studies on the deepfreezing technique for bull semen. III. Deep freezing of bull semen in pellet form. Japanese Journal of Animal Reproduction 9, 73-77.

Parrish, J.J., Susko-Parrish, J.L., Leibfried-Rutledge, M.L., Crister, E.S., Eyestone, W.H. \& First, N.L. (1986) Bovine in vitro fertilization with frozenthawed semen. Theriogenology 25, 591-600.

Platz, C.C. \& Seager, S.W.J. (1977) Successful pregnancies with concentrated frozen canine semen. Laboratory Animal Science 27, 1013-1016.

Platz, C.C., Wildt, D.E. \& Seager, S.W.J. (1978) Successful pregnancies in the domestic cat after artificial insemination with previously frozen spermatozoa. Journal of Reproduction and Fertility 52, 279-282.
Pursel, V.G., Johnson, L.A. \& Schulman, L.L. (1972) Loss of boar sperm fertilizing capacity associated with altered acrosome morphology during in vitro storage. Proceedings of the Seventh International Congress on Animal Reproduction and Artificial Insemination. Munich 2, 1595-1600.

Seal, U.S. \& Foose, T. (1983) Development of a masterplan for captive propagation of Siberian tigers in North American zoos. Zoo Biology 2, 241-244.

Steel, R.D. \& Torrie, J.H. (1960) Principles and Procedures of Statistics. McGraw-Hill, New York.

Wildt, D.E. (1990) Potential applications of IVF technology for species conservation. In Fertilization in Mammals, pp. 349-364. Eds B. D. Bavister, E. Roldan \& J. Cummins. Plenum Press, New York.

Wildt, D.E., Bush, M., Howard, J.G., O'Brien, S.J., Meltzer, D., van Dyk, A., Ebedes, H. \& Brand, D.J. (1983) Unique seminal quality in the South African cheetah and a comparative evaluation in the dom. estic cat. Biology of Reproduction 29, 1019-1025.

Wildt, D.E., Phillips, L.G., Simmons, L.G., Goodrowe, K.L., Howard, J.G., Brown, J.L. \& Bush, M. (1987) Seminal-endocrine characteristics of the tiger and the potential for artificial breeding. In Tigers of the World: The Biology, Biopolitics, Management and Conservation of an Endangered Species, pp. 255-279. Eds R. L. Tilson \& U. S. Seal. Noyes Publications, Park Ridge.

Wildt, D.E., Phillips, L.G., Simmons, L.G., Chakraborty, P.K., Brown, J.L., Howard, J.G., Teare, A. \& Bush, M. (1988) A comparative analysis of ejaculate and hormonal characteristics of the captive male cheetah, tiger, leopard and puma. Biology of Reproduction 38, 245-255.

Wildt, D.E., Donoghue, A.M., Johnston, L.A. \& Howard, J.G. (1992) Species and genetic effects on the utility of biotechnology for conservation. SymposiaZoological Society of London 64, 45-61.

Received 16 September 1991 